\title{
Whole-Genome Sequencing and Bioinformatics Analysis of Apiotrichum mycotoxinivorans: Predicting Putative Zearalenone-Degradation Enzymes
}

\author{
Jinyuan Sun ${ }^{\dagger}$, Yan Xia ${ }^{\dagger}$ and Dengming Ming* \\ College of Biotechnology and Pharmaceutical Engineering, Nanjing Tech University, Nanjing, China
}

\section{OPEN ACCESS}

Edited by:

Abd El-Latif Hesham,

Assiut University, Egypt

Reviewed by:

Fuguo Xing,

Institute of Food Science

and Technology (CAAS), China

Hua Fang,

Zhejiang University, China

*Correspondence:

Dengming Ming

dming@njtech.edu.cn

${ }^{\dagger}$ These authors have contributed equally to this work

Specialty section:

This article was submitted to

Food Microbiology,

a section of the journa

Frontiers in Microbiology

Received: 18 May 2020

Accepted: 15 July 2020

Published: 03 August 2020

Citation:

Sun J, Xia Y and Ming D (2020)

Whole-Genome Sequencing

and Bioinformatics Analysis

of Apiotrichum mycotoxinivorans:

Predicting Putative

Zearalenone-Degradation Enzymes.

Front. Microbiol. 11:1866.

doi: 10.3389/fmicb.2020.01866
Biological detoxification techniques have been developed by using microorganisms such as bacteria, yeast, and fungi to eliminate mycotoxin contamination. However, due to the lack of molecular details of related enzymes, the underlying mechanism of detoxification of many mycotoxins remain unclear. On the other hand, the next generation sequencing technology provides a large number of genomic data of microorganisms that can degrade mycotoxins, which makes it possible to use bioinformatics technology to study the molecular details of relevant enzymes. In this paper, we report the whole-genome sequencing of Apiotrichum mycotoxinivorans (Trichosporon mycotoxinivorans in old taxonomy) and the putative Baeyer-Villiger monooxygenases (BVMOs) and carboxylester hydrolases for zearalenone (ZEA) degradation through bioinformatic analysis. In particular, we developed a working pipeline for genome-scaled prediction of substrate-specific enzyme (GPSE, available at https://github.com/JinyuanSun/GPSE), which ultimately builds homologous structural and molecular docking models to demonstrate how the relevant degrading enzymes work. We expect that the enzyme-prediction woroflow process GPSE developed in this study might help accelerate the discovery of new detoxification enzymes.

Keywords: Apiotrichum mycotoxinivorans, whole-genome sequencing, mycotoxin detoxification, zearalenone (ZEA), BVMO, carboxylesterase, genome-scaled prediction of substrate-specific enzyme (GPSE)

\section{INTRODUCTION}

Many secondary fungal metabolites produced by a variety of molds from Fusarium, Aspergillus, and Penicillium are highly toxic and make up the majority of mycotoxins (Capcarova et al., 2016). In addition to the direct consequences of huge economic losses, the ubiquitous presence of mycotoxins in food and feed products also increases the risk of serious diseases, such as cancer, anamorphosis, dermatopathya, nephroma, and other non-specific symptoms, in both animal and human (Peraica et al., 1999; Hussein and Brasel, 2001). Therefore, a large number of tools are needed to remove a variety of mycotoxins from food and feed. Over the years, a wide spectrum of decontamination strategies have been developed by using physical [thermolysis, radiation treatment, etc. (Karlovsky et al., 2016)], chemical [oxidation, reduction, hydrolysis, absorption, etc. (Danicke et al., 2012)] and biochemical [by using biological agents (Vanhoutte et al., 2016)] techniques. Among these methods, the biodegradation of mycotoxins has become the most concerned method because of its costefficiency and green environmentally environmental friendliness. A number of microorganisms 
including bacteria, fungi, and yeasts have been found to be biodegradable, and the underpinning mechanisms are still under study.

The workhorses for microbial degradation are enzymes that efficiently convert mycotoxins into non-toxic or less toxic compounds (Ben Taheur et al., 2019). Therefore, it has become an indispensable task in the field of biodegradation to search for detoxifying enzymes and to characterize their catalytic activities, physicochemical properties, and three-dimensional structures (Loi et al., 2017; Lyagin and Efremenko, 2019). For example, aflatoxins are among the most toxic mycotoxins produced by fungus Aspergillus flavus and Aspergillus parasiticus, causing food and feed pollution and resulting in human cancers (Kuiper-Goodman, 1995). After decades of in-depth worldwide research, a bunch of enzymes from various organisms, such as bacteria, fungi, mammals, have been identified with aflatoxin biodegradability (Ben Taheur et al., 2019; Lyagin and Efremenko, 2019). Most of these enzymes are classified as aflatoxin dialdehyde reductase, which is characterized by the introduction of hydroxyl groups at C8 and C9 to open the bifuran ring (Kozma et al., 2003). This biotransformation is essential in eliminating aflatoxin's tumorigenicity. Enzymes that cut the aflatoxin coumarin ring was also identified, although the involved mechanisms are still unknown because of the lack of protein complex structures (Marimón Sibaja et al., 2019). In recent years, computer modeling technology has become more and more popular in the search for the next generation of aflatoxin degrading enzymes (Dhakal et al., 2017; Zarev et al., 2020).

Another important example is zearalenone (ZEA), a mycotoxin mainly produced by Fusarium, which happens to infect maize, barley, wheat, sorghum in various cool and humid seasons. The hormone-like structure of ZEA leads to hyperestrogenism symptoms, resulting in infertility and economic loss of animal husbandry. A carboxylesterase gene (ZHD101) has been reported to deactivate ZEA by opening the lactone ring (el-Sharkawy and Abul-Hajj, 1988; Takahashi-Ando et al., 2002), which was later verified by the X-ray crystal structures of enzyme-substrate and enzyme-product complexes (Peng et al., 2014; Qi et al., 2017). This enzyme is critically important for Clonostachys rosea to protect the plant from the wild type ZEA-producer Fusarium graminearum (Kosawang et al., 2014). However, the degradation products $\alpha-$ and $\beta-$ zearalenol (ZOL) still remain estrogenic biotoxicity (Vekiru et al., 2010). Peroxiredoxin and homologs were reported to non-specifically act on ZEA by oxidizing the double bond at $\mathrm{C} 1^{\prime} / \mathrm{C} 2$ ' and/or hydroxy-groups at $\mathrm{C} 2$ and $\mathrm{C} 4$ (Yu et al., 2012; Tang et al., 2013; Garcia et al., 2018). Vekiru et al. (2010) characterized the structural and estrogenic activity of the ZEA degradation products processed by Trichosporon mycotoxinivorans (T. mycotoxinivorans), a basidiomycete yeast used as a microbial feed additive against mycotoxins (Molnar et al., 2004; Schatzmayr et al., 2006). In their study, the main products of ZEA were identified and characterized by liquid chromatography-tandem mass spectrometry (LC- MS/MS) and LC-diode array detector (DAD) analysis. Their analysis suggested that ZEA was first oxidized by a Baeyer-Villiger oxidase (BVMO), resulting in the insertion of an oxygen atom between $\mathrm{C}^{\prime}$ ' and
C6'. The ring structure of this intermediate metabolite was then breaking at the newly formed ester bond with a carboxylesterase. However, both the BVMO and carboxylesterase enzymes in this degradation pathway remained unclear, which hindered their application in ZEA degradation.

In this paper, we report the whole-genome sequencing and annotation of T. mycotoxinivorans (Molnar et al., 2004), a strain recently renamed Apiotrichum mycotoxinivorans by Liu and collaborators in an integrated phylogenetic classification of the Tremellomycetes in 2015 (Liu et al., 2015). We then screened candidate BVMO and craboxylesterase genes for the ZEA-degradation with the GPSE workflow process. Homologous modeling and molecular docking are used to investigate the potent substrate-enzyme interactions. Pathogenomics of A. mycotoxinivorans were also investigated based on genome annotation, since the emergence of invasive infections have been recently reported (Almeida et al., 2017; Dabas et al., 2017).

\section{MATERIALS AND METHODS}

\section{Strains, Growth Condition and Genome Sequencing and Assembly}

The strain of A. mycotoxinivorans CICC 1454 was purchased from China Center of Industrial Collection (CICC), Building 6, No. 24 Courtyard, Jiuxianqiao Middle Road, Chaoyang District, Beijing, 100015). The fungus was cultured in Malt Agar (Malt extract $30 \mathrm{~g} / \mathrm{L}$, Agar $15 \mathrm{~g} / \mathrm{L}), 37^{\circ} \mathrm{C}, \mathrm{pH} 6$ for $24 \mathrm{~h}$. Considering that our strain was not exactly the same with Vekiru's, we first performed a LC-MS/MS analysis of the degradation products of ZEA by the strain and verified the reported singal $\mathrm{m} / \mathrm{z} 351$ (Supplementary Figure 1). Mycelia were collected and sent to Biomarker Technologies Corporation (Shunjie Building, No. 12 Fuqian Street, Shunyi District, Beijing, China) for genomic DNA extraction, sequencing, and assembly. The experimental process was implemented according to the standard protocol provided by Oxford Nanopore Technologies (ONT) company, including sample quality control, library construction, libraryquality detection, library sequencing, and other procedures (Jain et al., 2016). Particularly, genome sequencing was performed using the Nanopore and the Illumina platform. The error correction of subreads was conducted using Canu v1.5 (Koren et al., 2017) and assembled using wtdbg2 (Ruan and Li, 2020), and the second generation reads were aligned to the preliminary assembled genome for further error correction using Pilon (Walker et al., 2014).

\section{Annotation of Protein-Coding and Non-coding Components}

Repeat sequences in the genome were first identified and masked using two modules, RepeatMasker (Tarailo-Graovac and Chen, 2009) and RepBase (Bao et al., 2015), integrated in MAKER (Cantarel et al., 2008; Holt and Yandell, 2011). The conserved proteins of Basidiomycota, who locates at the nearest neighborhood of $A$. mycotoxinivorans in the phylogenetic tree (see below) (Liu et al., 2015), from BUSCO (Seppey et al., 2019) 
dataset were then retrieved and used as templates to identify homologous protein-coding regions in the genome by MAKER. The results were then processed with the module maker2zff in MAKER and converted to a ZFF format output, which was used by the gene prediction program SNAP (Korf, 2004) to generate a series of species-specific hidden Markov models for protein-coding gene prediction for the genome. The protein sequences obtained were finally compared with NCBI nonredundant datasets (nr) by using BLASTP (Sayers et al., 2020), and the candidates with an alignment $E$-value greater than $1 \mathrm{e}$ 3 were screened out for further analysis. The non-coding genes were annotated with Rfam (Griffiths-Jones et al., 2003), giving predictions of both rRNAs and snoRNAs; the tRNA genes were identified using tRNAscan-SE (Chan and Lowe, 2019).

\section{Phylogenetic Analysis}

Genomes of the strains in the same family as Apiotrichum, namely Apiotrichum brassicae, Apiotrichum domesticum, Apiotrichum gamsii, Apiotrichum gracile, Apiotrichum laibachii, Apiotrichum montevideense, Apiotrichum porosum, Apiotrichum veenhuisii, Cutaneotrichosporon arboriformis, Cutaneotrichosporon curvatum, Cutaneotrichosporon cyanovorans, Cutaneotrichosporon daszewskae, Cutaneotrichosporon dermatis, Cutaneotrichosporon mucoides, Cutaneotrichosporon oleaginosum, Takashimella koratensis, Trichosporon akiyoshidainum, Trichosporon asahii, Trichosporon coremiiforme, Trichosporon faecale, Trichosporon inkin, Trichosporon ovoides, are retrieved from NCBI.

The proteomic data of all but three species were predicted by the above-mentioned protein-coding component annotation method. The exceptional three species are A.porosum, T. asahii, and $C$. oleaginosum, whose proteome data can be downloaded directly from NCBI website. Orthologous proteins within different species were detected and clustered using the module proteinortho5.pl of the program Proteinortho (Lechner et al., 2011). Single copy of orthologous proteins are extracted and linked to one amino acid sequence using a Python3 script. Sequences are aligned using muscle (Edgar, 2004), then the phylogenetic tree is constructed using Minimum Evolution (ME) method and tested with bootstrap method with 999 replications. The plot of the phylogenetic tree was prepared using iTOL (Letunic and Bork, 2019).

\section{The Prediction of Detoxification Enzymes}

Screening the genome for enzymes that may catalyze the desired type of mycotoxin degradation involves several steps: assigning the catalytic-type for each predicted protein, modeling the homologous structures for selected candidate enzymes, docking the enzymes with the required substrate mycotoxin, and finally output a scoring function for each candidate enzyme according to the docking evaluation results.

The assignment of catalytic-type was implemented by scanning the annotated protein sequences against a preprocessed enzyme sequence database using BLASTP with an E-value cutoff 1e-5. The enzyme sequences were first download from BRENDA database (Scheer et al., 2011), then they were clustered using CD-HIT (Fu et al., 2012) to eliminate redundancy, and the representative enzyme with specific EC number was selected from each cluster. The percentage of cluster truncation was identified as 90\%, and the maximum length difference of class members was set as 60 amino acids. Proteins with specific EC numbers of interest were selected for further analysis, for example, sequences labeled with EC 3.1.1 were identified as carboxylesterase candidates. At this stage, specific catalytic motifs, if any, can be used for further screening. Only protein sequences identified by PfamScan (Bateman et al., 2004) that contain both $[\mathrm{A} / \mathrm{G}] \mathrm{GxWxxx}[\mathrm{F} / \mathrm{Y}] \mathrm{P}[\mathrm{G} / \mathrm{M}] \mathrm{xxxD}$ (Fraaije et al., 2002) and FxGxxxHxxxW[P/D] (Riebel et al., 2013) are considered BVMOs and were retained for further structural modeling and docking analysis. When their homology with protein sequences in the Protein Data Bank (PDB) exceeded $30 \%$, the 3D structures of the enzymes were then built using MODELLER (Webb and Sali, 2017). Giving the structure, the ligand-binding sites were predicted on these structures using P2RANK (Krivák and Hoksza, 2018) with default parameters. Then, AutoDock vina (Trott and Olson, 2010) was used to dock the desired substrate, ZEA and ZOM in this work, to the predicted ligand-binding sites. A scoring function was assigned to each enzyme as the calculated binding energy. Other constraints, such as the distance between the active center and the substrate, were also be used as an auxiliary scoring function to help enzyme candidate screening. This workflow process, called Genomescaled Prediction of Substrate-specific Enzymes (GPSE), has been integrated into a pipeline with a Python3 script, which is available at https://github.com/JinyuanSun/GPSE.

\section{Specialized Bioinformatics Analysis}

The predicted protein sequences of $A$. mycotoxinivorans were upload to EggNOG server 4.5 (Huerta-Cepas et al., 2016) for clusters of orthologous groups (COG) assignment for further protein function characterization. The CAZymes were predicted by scanning against the dbCAN database (Yin et al., 2012; Huang et al., 2018) using HMMER v3.3 (Eddy, 1998) with default parameters. PHI-related genes, CYP450s, and peptidases were predicted by scanning against PHI-base (Winnenburg et al., 2006, 2007; Urban et al., 2015), fungal cytochrome p450 database (Park et al., 2008) and MEROPS (Rawlings and Barrett, 1999; Rawlings et al., 2010, 2017), respectively, using BLASTP (Altschul et al., 1997 ) with an $E$-value cut-off of 1e-10. Transmembrane domains, signal peptides were prepared using TMHMM (Krogh et al., 2001) and TargetP-2.0 (Emanuelsson et al., 2000, 2007) with their default parameters. Biosynthetic gene clusters (BGCs) in the genome and the corresponding secondary metabolites were predicted using the webserver of the antiSMASH 5.0 fungal version (Blin et al., 2017, 2019). All parameters were default.

\section{RESULTS}

\section{Genome Sequencing and Assembly}

After two rounds of error correction, 7,236 $\mathrm{Mb}$ raw sequence reads of $A$. mycotoxinivorans obtained from Nanopore sequencing platform gave the final genome sequence. The basic statistics of the sequencing is given in Table 1. The genome 
TABLE 1 | The statistical results of the genome assembly of $A$. mycotoxinivorans.

\begin{tabular}{lc}
\hline Number of contigs & $\mathbf{7}$ \\
\hline Total length (bp) & $30,749,651$ \\
N50 (bp) & $7,496,769$ \\
N90 (bp) & $3,077,865$ \\
Max length (bp) & $10,254,415$ \\
Min length (bp) & 137,936 \\
GC content (\%) & 57.57 \\
\hline
\end{tabular}

is assembled into 7 contigs with a total length of 30,749,651 bp, which is similar to that of most Trichosporonaceae fungi whose sizes fall in the range between 20 and $40 \mathrm{M}$. The genome has been uploaded to NCBI under Bioproject accession PRJNA633776 and Genome Assembly accession GCA_013177335.1.

\section{Phylogenetic Analysis}

In order to construct the phylogenetic tree of A. mycotoxinivorans, the genome sequences of 22 species of Trichomonidae (Cutaneotrichosoron, Trichosporon and Apiotrichum) were downloaded from the NCBI website, using Takashimella koratensis as the outgroup. For all species without the protein-coding sequences determined by experiments, we constructed SNAP hidden Markov model with Basidiomycota conservative proteins download from BUSCO and annotated the proteins from scratch. The phylogenetic tree was based on orthologous amino acid sequences of the 23 selected genomes and constructed with the program Proteinortho v6 with the $T$. koratensis as the outgroup. The results can be obtained on our website ${ }^{1}$. Phylogenetic tree analysis showed that A. mycotoxinivorans belongs to the genus Apiotrichum and is most closely related to $A$. veenhuisii (Figure 1). The profile of this phylogenetic tree is consistent with the phylogenetic classification of Tremellomycetes reported previously, and the classification is further confirmed (Liu et al., 2015). Also, in this phylogenetic tree, T. akiyoshidainum should be renamed as A. akiyoshidainum.

\section{Prediction and Annotation Coding and Non-coding Components}

905 tRNA genes and pseudogenes were predicted by tRNAscanSE 2.0 (Chan and Lowe, 2019), among them 835 tRNA genes contain 46 unique anti-codons. The number of 5.8S rRNA, $18 \mathrm{~S}$

${ }^{1}$ https://minglab.tk/amzeadegrade.html

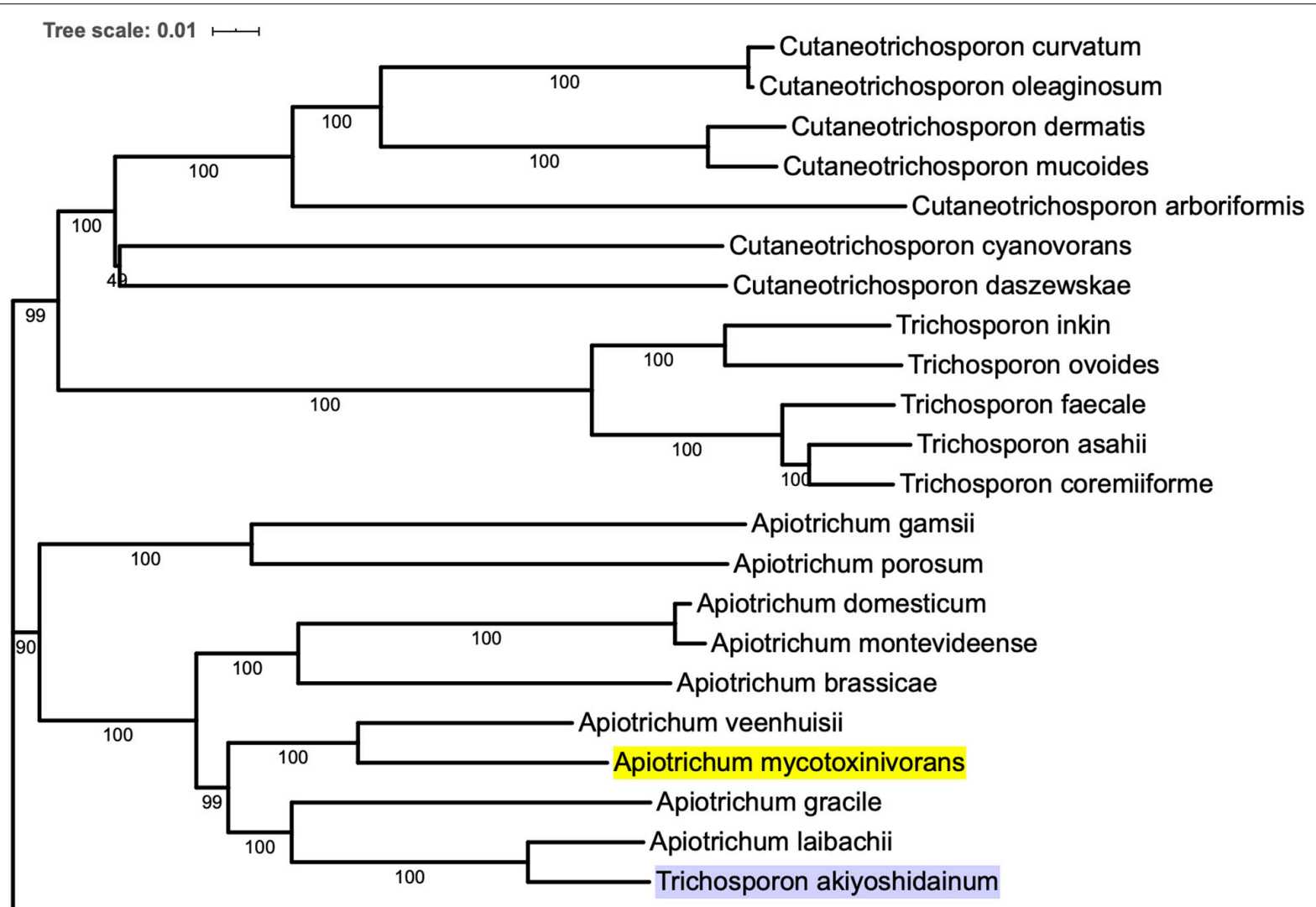

Takashimella koratensis

FIGURE 1 | The phylogenetic tree was inferred based on orthologous amino acid sequences of the 23 selected Tremellomycetes genomes using Proteinortho v6, ME method is used in the phylogenetic tree, and the T. koratensis is the outgroup. The background color of $A$. mycotoxinivorans is highlighted with bright yellow and T. akiyoshidainum is highlighted with light purple. 
rRNA, and $28 \mathrm{~S}$ rRNA were 1,2 , and 3, respectively. Due to the lack of transcription data, we combined the evidence from BUSCO database to train SNAP HMM model for protein-coding sequence prediction from scratch. Among the predicted 10922 protein sequences of $A$. mycotoxinivorans, 9404 homologous protein sequences were identified in NCBI NR database, 8669 of which could be assigned as orthologous seeds by eggnog-mapper v4.5.1. 8163 proteins were assigned a one-letter coded Clusters of Orthologous Groups of proteins (COGs) (Figure 2). 4693 sequences $(54.13 \%)$ are assigned to gene ortholog (GO) terms. For detailed function prediction, more tools are needed. 1536 proteins predicted have transmembrane helix and 642 proteins with signal peptides.

\section{Carbohydrate-Active Enzymes Annotation}

Carbohydrate active enzymes (CAZymes) are essential enzymes to decompose the components of host cell walls during infection. Extracellular CAZymes are usually involved in plant adhesion and initial infection. The CAZy database records both catalytic and non-catalytic proteins involved in the synthesis and breakdown of complex carbohydrates and glycoconjugates. The database dbCAN-seq is a collection of CAZymes sequence and annotations (Huang et al., 2018). The analysis based on dbCANseq database shows that 462 genes encode CAZymes (Figure 3A), which are divided into 6 categories and 102 CAZy families. Among these genes, 59 proteins have transmembrane domains and 44 have signal peptides.

\section{Pathogenetic Proteins Involved in Pathogen-Host Interaction}

Apiotrichum mycotoxinivorans is a human pathogen, especially in cystic fibrosis patients with lung infections (Almeida et al., 2017). To the best of our knowledge, although some relevant clinical cases have been reported, the pathogenic genes have not been successfully identified in A. mycotoxinivorans due to the lack of genomic resources. In order to obtain the putative genes associated with the pathogenicity and

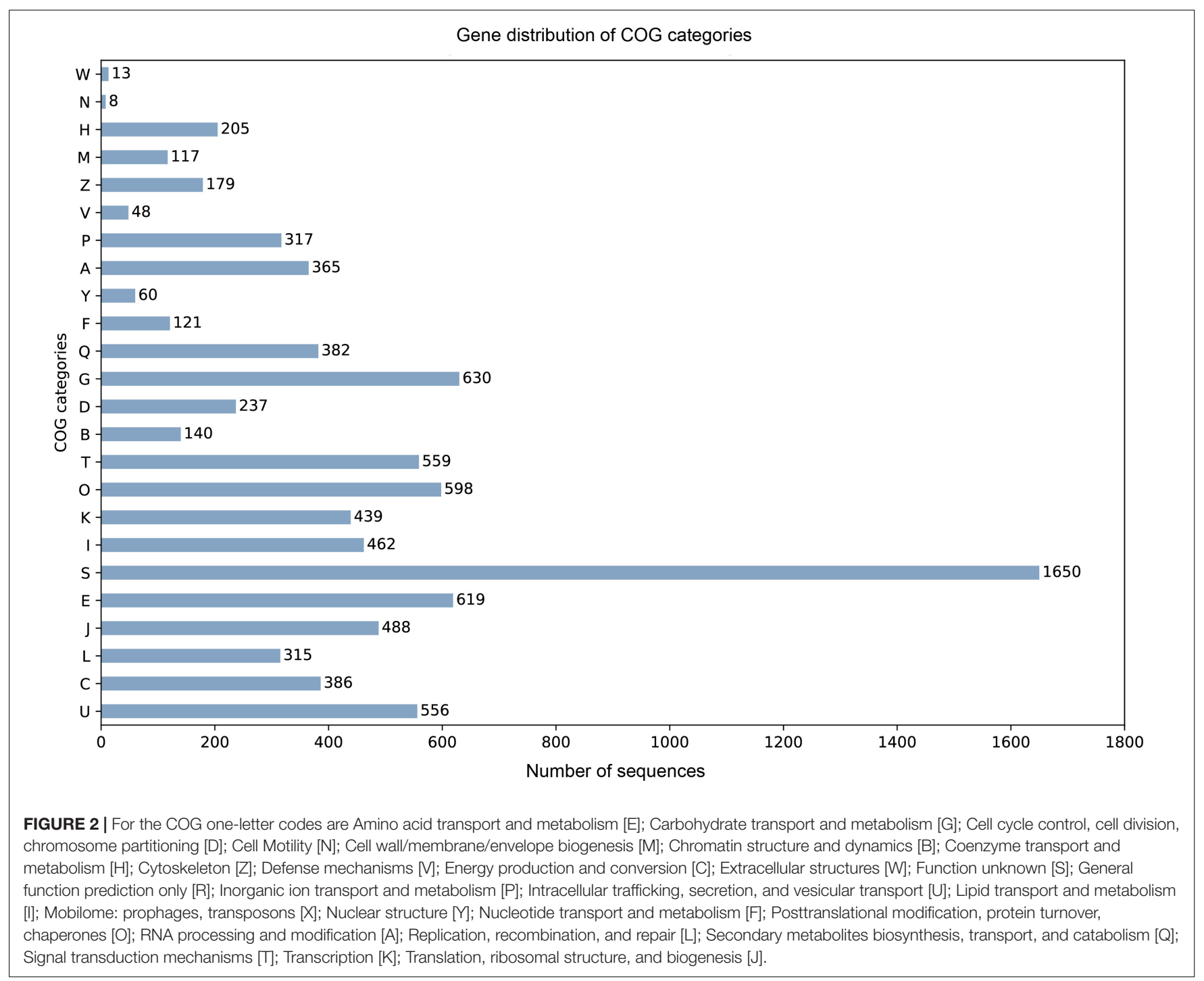


A

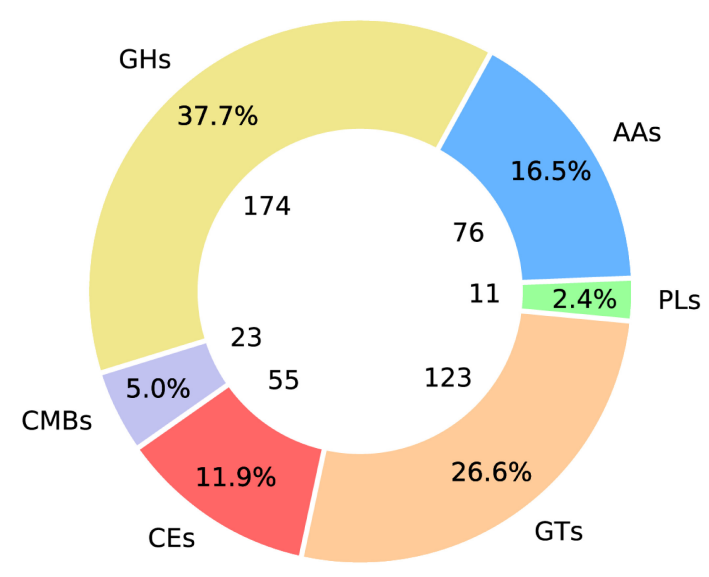

C

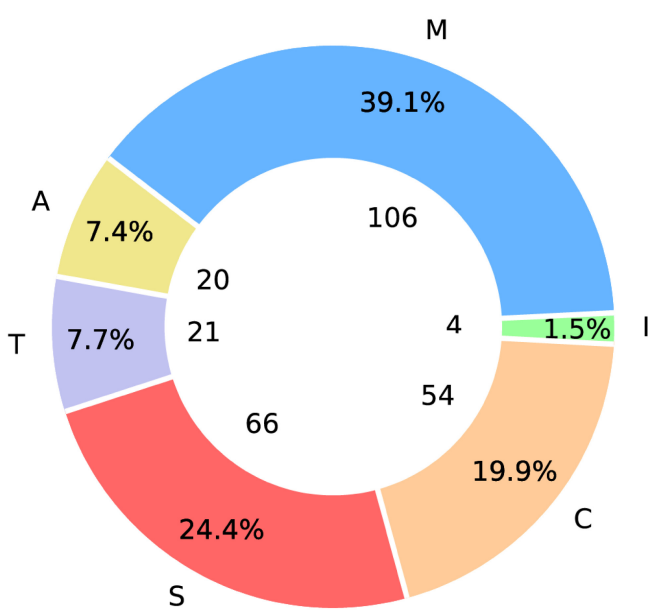

B

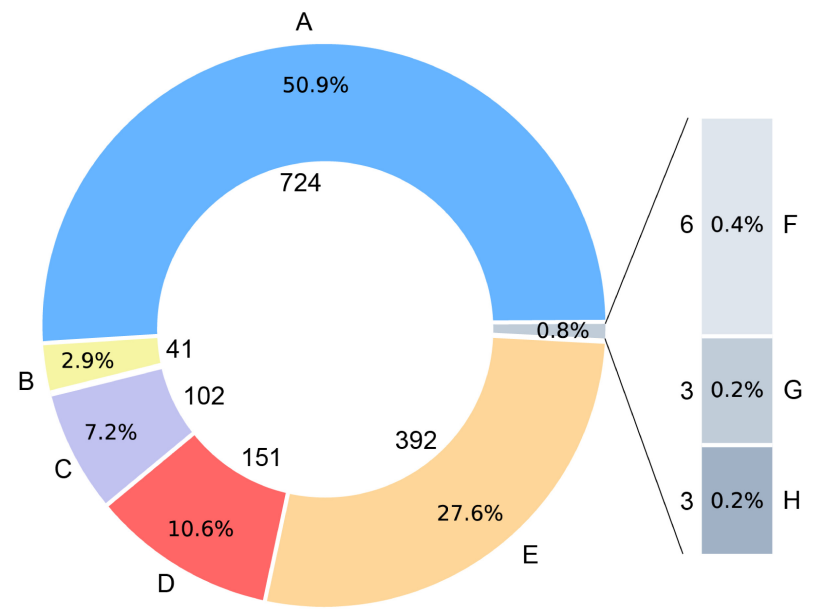

D

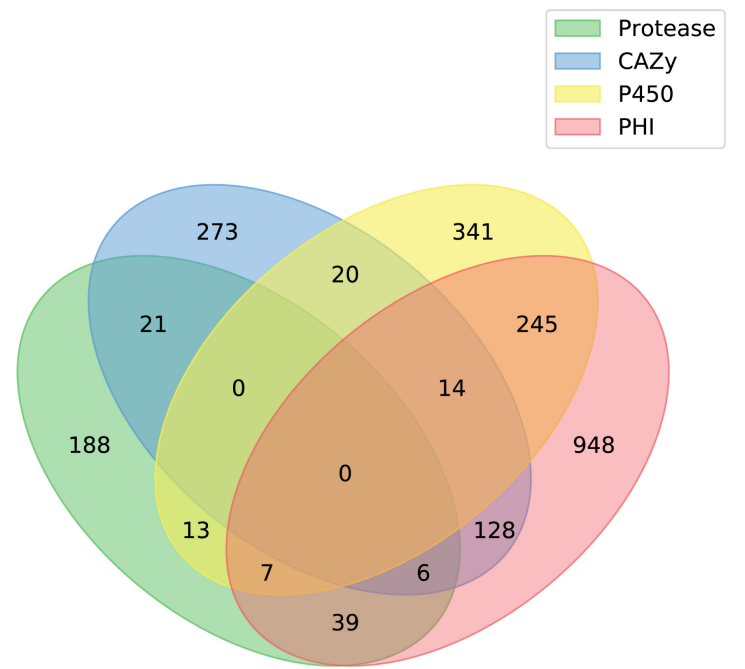

FIGURE 3 | Pie plots of distribution of CAZymes, PHI related proteins and proteases and venn graph of intersection of proteses, CAZymes, PHI related proteins and CYP450. (A) 174 genes distributed in 45 families, which encode glycoside hydrolases (GHs) and 5 of them containing a carbohydrate-binding module (CBM). 123 glycosyltransferases (GTs) distributed across 27 families. 23 genes are encoding CBM proteins (CBMs), which belong to 7 families, and their main function is to bind to crystalized cellulose, granular starch, and other substrates. Also, there are 76 proteins with auxiliary activities (AAs), which involving in redox activities required by the breakdown of lignin, which implies A. mycotoxinivorans may be of redox activities. (B) Pie plot distribution of proteases. 106 genes distributed in 31 families, which encode metallopeptidases (M). 54 cysteine peptidases (C) distributed across 16 families. 66 genes are serine peptidases (S), which belong to 12 different families, 20 protein sequences annotated as aspartic peptidases (A), fall into 2 families. 21 proteins are predicted to be threonine peptidases (T) within 4 families. Also, there are 4 proteins are peptidase inhibitors, distributed in 25 families, which of great importance to maintain the balance within organisms. (C) Pie plot distribution of pathogen and host interaction (PHI). PHI classified as: reduced virulence $(A)$, increased virulence or hypervirulence (B), lethal $(\mathrm{C})$, loss of pathogenicity (D), unaffected pathogenicity (E), chemistry target: resistance to chemical (F), effector (plant avirulence determinant) (G), chemistry target: sensitivity to chemical (H). (D) Venn graph showing the intersections among the proteases (green), CYP450 enzymes (yellow), CAZymes (blue), and PHI proteins (pink).

antibiotic resistance, we further analyzed the proteome of A. mycotoxinivorans using the pathogen-host interaction (PHI) gene database (Winnenburg et al., 2006, 2007; Urban et al., 2015). 1387 protein-coding genes were predicted to be associated with the pathogenicity of $A$. mycotoxinivorans, 53 of which are secretory proteins and 300 have transmembrane domains.

The distribution of PHI related proteins was predicted as follows (Figure 3B): 724 virulence decreased, 41 virulence increased or hypervirulent, 102 lethal, 151 pathogenicity lost, 392 pathogenicity unaffected, 3 chemistry targets: resistance to chemical, 3 effector (plant avirulence determinant), and 6 chemistry targets: sensitivity to chemical.

\section{Annotation of Proteases in Genome}

Peptidases are enzymes that catalyze the hydrolysis of peptide bonds, which is very important for the survival of organisms. About $2 \%$ of the genes in the genome are encoded (Rawlings and Barrett, 1999; Rawlings et al., 2017). Peptidases are considered to destroy host tissues and provide nutrients for pathogen reproduction. Some extracellular peptidases are also involved 
TABLE 2 | Four Biosynthetic gene clusters predicted in A. mycotoxinivorans.

\begin{tabular}{lccc}
\hline Cluster ID & Type & Gene number & Similar gene clusters number \\
\hline AmBGC_1 & Terpene & 6 & 0 \\
AmBGC_2 & terpene & 11 & 1 \\
AmBGC_3 & NRPS-like & 11 & 10 \\
AmBGC_4 & NRPS-like & 10 & 1 \\
\hline
\end{tabular}

in cell wall maintenance and remodeling, adhesion to the host's external protective barrier, deregulation of the host protein hydrolase cascade, and inactivation of host antimicrobial peptides. The peptidase genes in A. mycotoxinivorans were annotated by using the MEROPS database (MEROPS 12.0,
September 2017) (Rawlings et al., 2017). A total of 267 genes were predicted to be peptidases (Figure 3C), including metallopeptidase, cysteine peptidase, serine peptidase, aspartate peptidase and threonine peptidase, which is consistent with the distribution proportion of peptidase genes in the genome. In addition, four genes were predicted to be inhibitors. Among these genes, 11 proteins have transmembrane domains and 11 have signal peptides. These secreted peptidases might be involved in the infection of $A$. mycotoxinivorans.

\section{Cytochrome P450 Enzymes in}

\section{A. mycotoxinivorans}

Cytochrome P450 (CYP450) plays an important role in the primary metabolism of fungi, involving the integrity of cell
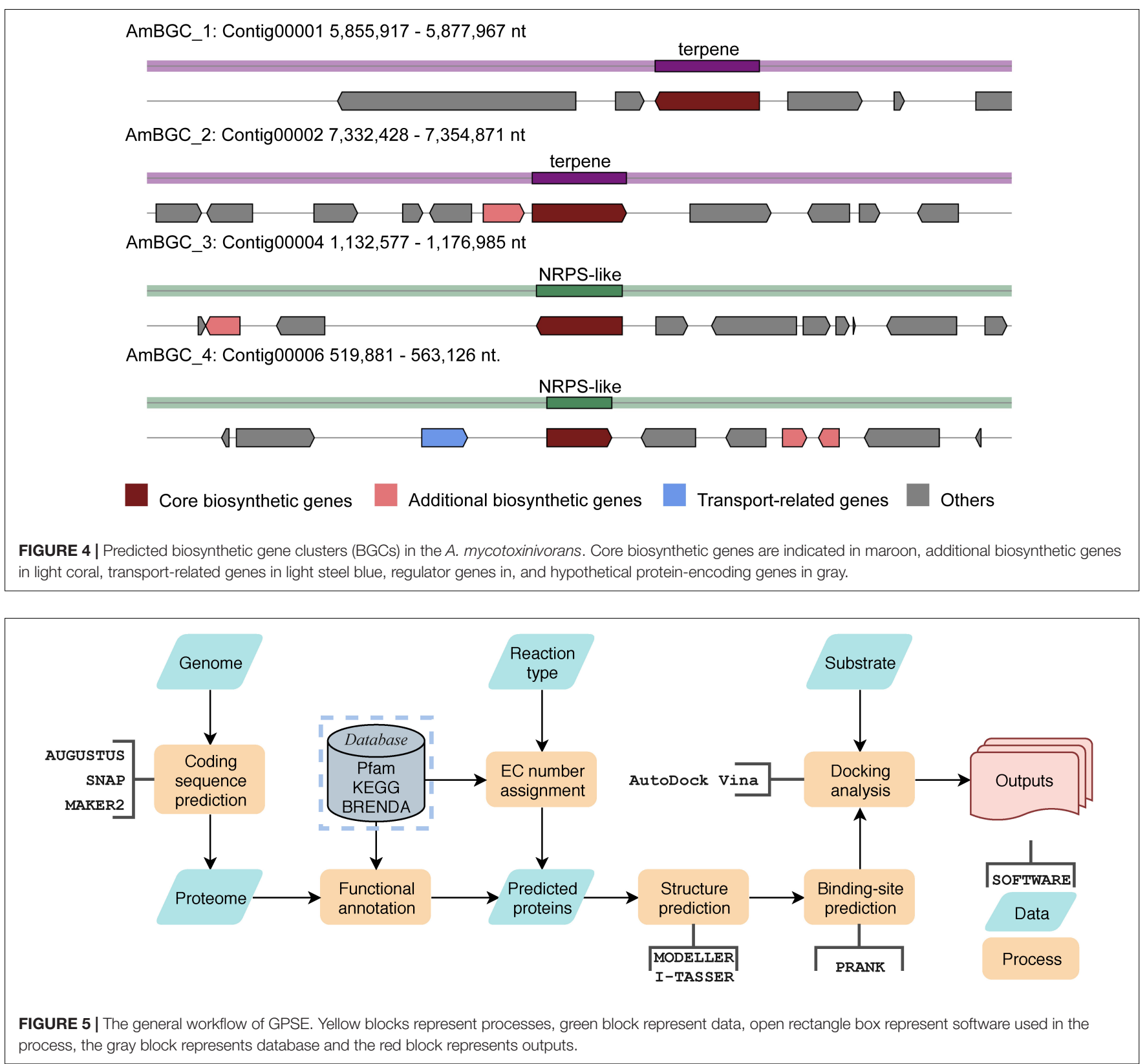
wall and formation of the spore outer wall. So far, several CYP450s have been found in fungi, which catalyze reactions in the pathways of mycotoxin synthesis, hormone production, detoxification, fatty acid hydroxylation, etc. By scanning the CYP450 database of fungi (Park et al., 2008) with BLATP, we identified 640 putative CYP450s in A. mycotoxinivorans. Among them, 38 proteins were predicted to have signal peptides and 183 genes to have transmembrane domains. The cross-coverage of CYP450s, CAZymes, PHI proteins, and Peptidase is shown in Figure 3D.

\section{The Biosynthetic Potential of A. mycotoxinivorans}

Many fungi can produce secondary metabolites, which can be drugs or precursors of drugs, with genes that are contiguously arranged in biosynthetic gene clusters (BGCs) (Rokas et al., 2020). We used the program antiSMASH 5.0 (Blin et al., 2019) to analyze the genome of A. mycotoxinivorans and identified 4 BGCs on the four different contigs (Table 2 and Figure 4). Although the amount of BGCs in mycoplasma is very small, AmBGC_1 was identified to produce a new terpenoid compound, because no similar BGCs have been found. The core gene of AmBGC_2 is $63.4 \%$ similar to that of oxidosqualene clavarinone cyclase (OCC) which is essential to clavaric acid biosynthesis in Hypholoma sublateritium (Godio et al., 2007). This suggests that A. mycotoxinivorans may be able to produce clavulanic acid, an anti-tumor product. No BGCs with significant similarity to AmBGC_3 and AmBGC_4 have been found. These BGCs may produce some new compounds, which need to be characterized by wet experiments in the laboratory.

\section{Prediction of Enzymes Involving Mycotoxin Degradation}

As mentioned before, A. mycotoxinivorans can detoxify ZEA through the destruction of molecular structure rather than through masking. In order to screen mycotoxin degrading enzymes genome, we developed a workflow of Genome-scaled Prediction of Substrate-specific Enzymes termed as GPSE (Figure 5). Two BVMO candidate enzymes have been found in the genome using BVMO-specific sequence motifs (Mascotti et al., 2015), of which protein C1_1820 is the enzyme most likely to oxidize ZEA to the zearalenone oxidized metabolite (ZOM). The newly formed ester bond at $\mathrm{C}^{\prime}$ in $\mathrm{ZOM}$ can be hydrolyzed by the carboxylesterase of A. mycotoxinivorans, which breaks the macrocyclic ring of ZEA at the ketone group at C6'. By comparing the predicted proteins with the enzymes in the Brenda database (Jeske et al., 2019), GPSE predicted 3157 hypothetical enzymes, of which 76 were carboxylesterases. We have built 42 predicted carboxylesterase homology models by the MODELER program (Webb and Sali, 2017) with a minimum sequence homology of $30 \%$. ZOM was well docked to 32 binding sites in the 17 models, and it was found that the putative enzymes C2_44, C3_70, and C5_1043 were most likely to hydrolyze the newly formed ester bonds of ZOM by visual inspection.

\section{DISCUSSION AND CONCLUSION}

Apiotrichum mycotoxinivorans is a very valuable fungus that can degrade and detoxify mycotoxin. It has been widely used in feed additives. However, it is also a human pathogen that can cause lung infection, especially in patients with cystic fibrosis. In this study, the whole genome of $A$. mycotoxinivorans was sequenced, assembled, and analyzed. The genome of A. mycotoxinivorans contains 30 million base pairs, which is similar to that of most of the sequenced Tremellomycete strains. In this work, we assembled the genome into 7 contigs, and considering that the seventh contig is very small, it should be part of other long chromosomes. We noted that researchers in Guangzhou Medical University had very recently uploaded genomic data of A. mycotoxinivorans GMU1709 with 6 contigs. Compared their genome data, the 6th and 7th contigs in this study are mostly likely to come from the same chromosome. We predicted the coding and non-coding components in the genome by interpreting the assembly data. The phylogenetic relationships of most of the sequenced strains in Tremellomycetes were analyzed by using the gene tree constructed from homologous proteins, which confirmed that the classification of A. mycotoxinivorans was consistent with the previous studies by Liu et al. (2015). The organization and distribution of tRNA genes and pseudogenes in genomes showed complex lineage-specific patterns.

In the genomes of all sequenced strains of Apiotrichum, Cutaneotrichosporon, and Trichosporon, the number of tRNA copies is very high, about $20 \sim 40$ copies per Mbp on average, which is much higher than that of $T$. koratensis. T. koratensis is used as an outgroup reference in phylogenetic analysis. The phylogenetic tree suggested that $T$. akiyoshidainum should be also classified as A. akiyoshidainum. Of 1387 pathogenhost interaction genes of $A$. mycotoxinivorans, 50\% were categorized as virulence-related protein with reduced toxicity, followed by unaffected pathogenicity and pathogenicity loss, and 102 genes predicted to be lethal. Among 462 predicted carbohydrate enzymes, glycoside hydrolases (GHS) are the most common enzymes, followed by the glycosyltransferases (GTs) and auxiliary activities (AAs) which are redox enzymes acting together with CAZymes. A. mycotoxinivorans is not considered to be a plant pathogen, but the presence of AAs has the redox capability needed for lignin decomposition, indicating that it may have the potential to degrade agricultural wastes. The number of cytochrome-P450 enzymes and proteases was 640 and 267, respectively. Some proteases, which are also predicted to be PHI proteins, are likely to be involved in infection. A. mycotoxinivorans is sensitive to most antifungal drugs, which means these CYP450 variants are not resistant.

In recent years, a lot of researches have been done on the biodegradation mechanism of ZEA, but most of them are based on the hydrolysis of the lactone bond of ZEA at C12' (Peng et al., 2014; Qi et al., 2017) and the product ZOLs still has estrogenic biotoxicity. It was reported that $A$. mycotoxinivorans can degrade ZEA in two steps into a non-estrogenic compound (Vekiru et al., 2010; Figure 6A). First, it uses a BVMO enzyme to catalyze the insertion of an oxygen atom between $\mathrm{C5}^{\text {' and } \mathrm{C} 6 \text {, }}$ 
(A)<smiles>CC1CCCC(=O)CCC/C=C/c2cc(O)cc(O)c2C(=O)O1</smiles>

$\mathrm{O}_{2}+\mathrm{NAD}(\mathrm{P}) \mathrm{H}+\mathrm{H}^{+}$

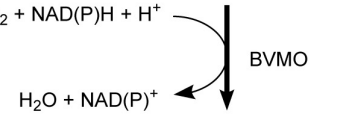<smiles>C[C@H](CCCCOC(=O)CCC/C=C/c1cc(O)cc(O)c1C(=O)O)OC(=O)[C@H](C)CO</smiles><smiles>C[C@H](C/C=C/c1cc(O)cc(O)c1C(=O)O[C@@H](C)CCCC(=O)O)CCCO</smiles>

Futher metabolism

(C)

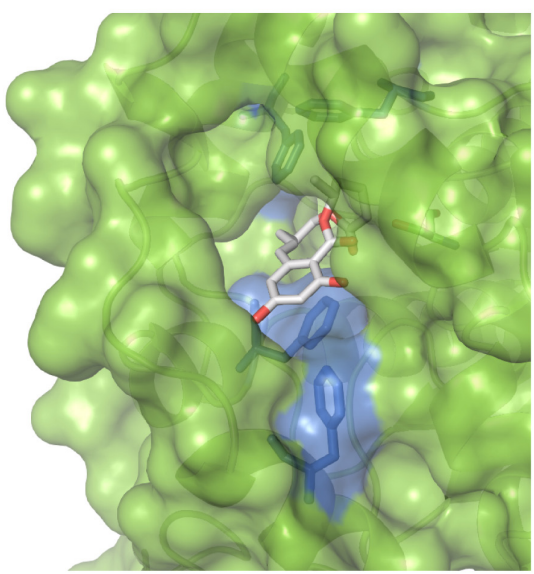

(E)

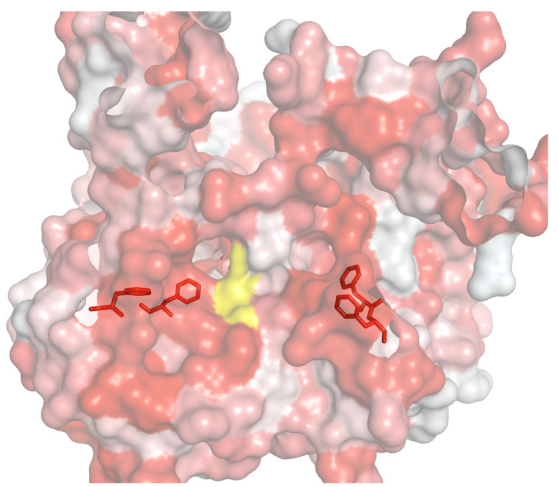

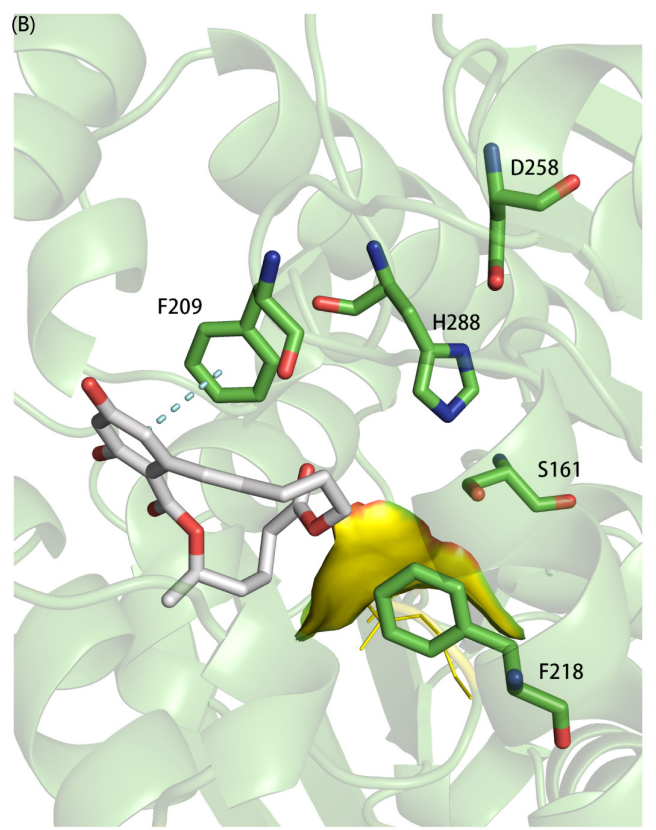

(D)
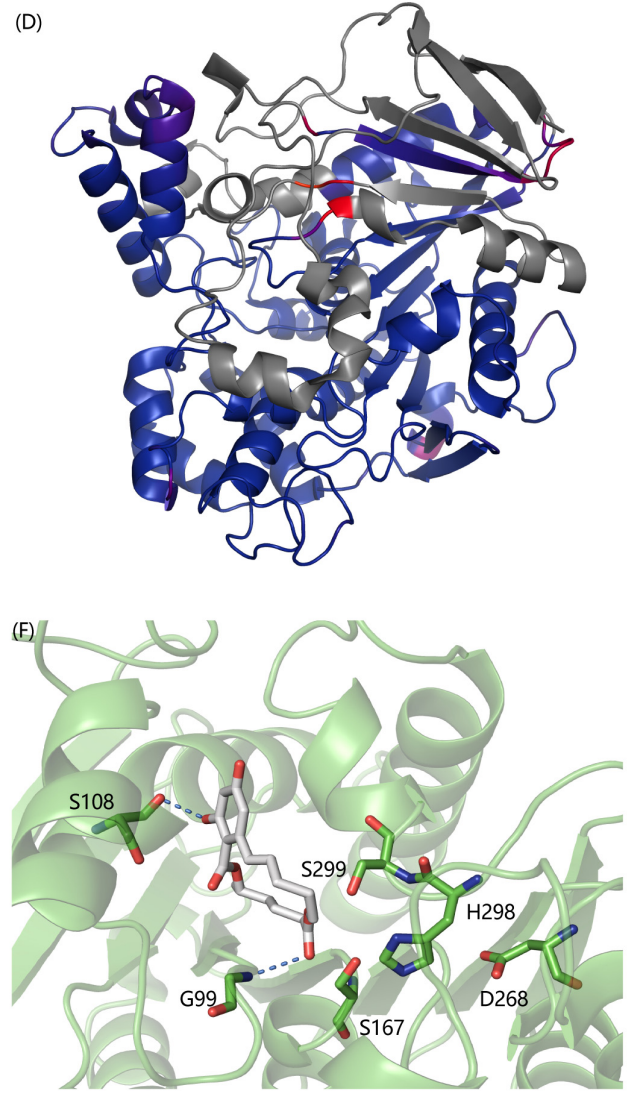

FIGURE 6 | (A) The degradation process of ZEA. (B) Predicted binding pose of ZON to C2_44, the yellow surface is a highly flexible loop region G88-G89-G90 which may involve the formation of oxyanion hole. (C) The aromatic tunnel of C2_44, the surface is in green and the most hydrophilic surface is in blue. Aromatic amino acids within $4 \AA$ of ZON were shown in stick. (D) The comparison of C3_70 and 4BE4, agreed parts in structures colored blue and extra parts colored in gray and identical but not agreed parts colored red and purple. (E) The aromatic flank of C3_70, the most hydrophobic surface is in red and the most hydrophilic surface is in white. The yellow surface is exposed part of catalytic triad. Aromatic amino acids on the surface forming the flank were shown in stick. (F) The binding poses of ZON to C5_1043. S108 and G99 involved formation of hydrogen bonds to stabilize the complex. S167-H298-D268 formed the typical catalytic triad. However, the S299 also in acceptable geometry forming a catalytic triad with H298-D268 and to carry out a nucleophilic attack on the carbonyl of the ester group. The structural figures were prepared using PYMOL (http://pymol.org). 
thus transferring the cyclic ketone to some zearalenone oxidized metabolite (ZOM). Next, some carboxylate ester hydrolase is recruited to hydrolyze ZOM, breaking the ester bond at C6' to produce non-estrogen compounds (ZOM-1). However, as far as we know, the sequences of BVMO that oxidizes ZEA to ZOM (or ZEA-BVMO) and that of carboxylesterase that hydrolyzes ZOM (or ZOM-HD) have not been reported to be related to the oxidization and hydrolysis of ZEA at C6'. In this study, a workflow processing, called genome-scale prediction of substrate-specific enzymes (GPSE), was developed to screen ZEA-BVMO and ZOM-HD in silico from the genome of A. mycotoxinivorans. In particular, among the two predicted ZEA-BVMO candidates from GPSE, ZEA can dock in the substrate-binding pocket of C1_1820 structural model with an acceptable binding affinity of $-5.9 \mathrm{kcal} / \mathrm{mol}$, but it is difficult to dock with C2_51. Therefore, our results showed that C1_1820 is more likely to be the ZEA-BVMO enzyme. 32 putative ZOM-HDs predicted from GPSE were subjected to additional examination based on active-sites and protein-family annotation by using PfamScan. Three proteins were selected as putative ZOM-HDs as follows.

C2_44 belonging to the Abhydrolase_3 family (PF07859) has 49.8\% homology with Est2349 from Thalassospira sp. GB04J01 (PDB ID: 4V2I). In the initial docking model, the aromatic ring in ZON was controlled by F209. Because the unfavorable position of the highly flexible loop G88-G89-G90 blocked the catalytic triad (S161-H288-D258), the distance between the carbon in the ester and S161 was $6.5 \AA$ (Figure 6B). In addition, the tunnel surface is highly hydrophobic, which corresponds to another lactonase that hydrolyzes ZEA, and hydrophobic and aromatic interactions are important for substrate recognition (Figure 6C).

C3_70 is annotated as COesterase, a carboxylesterase belonging to protein family PF00135. It has 59.7\% homology with a carboxylic esterase from Ophiostoma piceae [PDB ID:4BE4 (Gutierrez-Fernandez et al., 2014)]. However, despite the high homology between C3_70 and the esterase of O. piceae, C3_70 lacks a very long fragment, which is a cap domain in the hydrolase structure of $O$. piceae (Figure 6D). After carefully examining the $a b$ initio gene predictions and ensuring that the missing part is not mistaken deleted for the intron, we think it is reasonable to assume that the function of cap deficient hydrolase is different from that of another enzyme. The lack of a cap may lead to a broader substrate spectrum. The surface around the active site is highly hydrophobic and forms aromatic side groups (Figure 6E), indicating that C3_70 can even hydrolyze ester bonds in polymers such as polyethylene terephthalate (PET) or lignin.

C5_1043 has 39.6\% homology with HSL-like carboxylesterase of Sulfolobus tokodaii, which is annotated as the Abhydrolase_3 family. Among all the candidate hydrolytic enzymes identified by

\section{REFERENCES}

Almeida, J. N. Jr., Francisco, E. C., Barberino, M., Silva, L. F., Brandao, O. M., Colombo, A. L., et al. (2017). Emergence of Trichosporon mycotoxinivorans (Apiotrichum mycotoxinivorans) invasive infections in Latin America. Mem. Inst. Oswaldo Cruz 112, 719-722. doi: 10.1590/0074-027601 70011
GPSE, C5_1043 has the highest binding affinity with ZEA, which was $-9.5 \mathrm{kcal} / \mathrm{mol}$. Because the surface of the substrate-binding pocket is not aromatic, the complex is stabilized by two hydrogen bonds and hydrophobic interactions (Figure 6F).

In summary, in the paper the genomic data of A. mycotoxinivorans were systematically and comprehensively analyzed to screen for ZEA-degrading oxidoreductases and hydrolases. We developed an annotation pipeline GPSE based on genomic data to predict substrate-specific enzymes, and established three-dimensional structure models to study the mechanism of oxidative degradation of ZEA catalyzed by monooxygenase. The workflow process GPSE developed in this study might help to accelerate the discovery of new enzymes for mycotoxin degradation.

\section{DATA AVAILABILITY STATEMENT}

The datasets presented in this study can be found in online repositories. The names of the repository/repositories and accession number(s) can be found in the article/Supplementary Material.

\section{AUTHOR CONTRIBUTIONS}

DM conceived and designed the research. JS and YX performed the experiments and contributed to the reagents, materials, and analysis tools. JS, YX, and DM analyzed the data. DM and JS wrote the manuscript. All authors read and approved the manuscript.

\section{FUNDING}

This work was supported, in part, by the National Key Research and Development Program of China (Grant Nos. 2019YFA0905701 and 2017YFC1600900) and by the Key University Science Research Project of Jiangsu Province (Grant No. 17KJA180005).

\section{SUPPLEMENTARY MATERIAL}

The Supplementary Material for this article can be found online at: https://www.frontiersin.org/articles/10.3389/fmicb. 2020.01866/full\#supplementary-material

FIGURE S1 | Full-scan spectrum (ESI negative mode) of the ZEA metabolites. The $351 \mathrm{~m} / \mathrm{z}$ is the signal of $[\mathrm{M}-\mathrm{H}]$.

Altschul, S. F., Madden, T. L., Schäffer, A. A., Zhang, J., Zhang, Z., Miller, W., et al. (1997). Gapped BLAST and PSI-BLAST: a new generation of protein database search programs. Nucl. Acids Res. 25, 3389-3402. doi: 10.1093/nar/25.17. 3389

Bao, W., Kojima, K. K., and Kohany, O. (2015). Repbase update, a database of repetitive elements in eukaryotic genomes. Mob. DNA 6:11. doi: 10.1186/ s13100-015-0041-9 
Bateman, A., Coin, L., Durbin, R., Finn, R. D., Hollich, V., Griffiths-Jones, S., et al. (2004). The Pfam protein families database. Nucl. Acids Res. 32(Suppl. 1), D138-D141. doi: 10.1093/nar/gkh121

Ben Taheur, F., Kouidhi, B., Al Qurashi, Y. M. A., Ben Salah-Abbes, J., and Chaieb, K. (2019). Review: biotechnology of mycotoxins detoxification using microorganisms and enzymes. Toxicon 160, 12-22. doi: 10.1016/j.toxicon.2019. 02.001

Blin, K., Medema, M. H., Kottmann, R., Lee, S. Y., and Weber, T. (2017). The antiSMASH database, a comprehensive database of microbial secondary metabolite biosynthetic gene clusters. Nucl. Acids Res. 45, D555-D559. doi: 10.1093/nar/gkw960

Blin, K., Shaw, S., Steinke, K., Villebro, R., Ziemert, N., Lee, S. Y., et al. (2019). antiSMASH 5.0: updates to the secondary metabolite genome mining pipeline. Nucl. Acids Res. 47, W81-W87. doi: 10.1093/nar/gkz310

Cantarel, B. L., Korf, I., Robb, S. M., Parra, G., Ross, E., Moore, B., et al. (2008). MAKER: an easy-to-use annotation pipeline designed for emerging model organism genomes. Genome Res. 18, 188-196. doi: 10.1101/gr. 6743907

Capcarova, M., Zbynovska, K., Kalafova, A., Bulla, J., and Bielik, P. (2016). Environment contamination by mycotoxins and their occurrence in food and feed: physiological aspects and economical approach. J. Environ. Sci. Health B 51, 236-244. doi: 10.1080/03601234.2015.1120617

Chan, P. P., and Lowe, T. M. (2019). tRNAscan-SE: searching for tRNA genes in genomic sequences. Methods Mol. Biol. 1962, 1-14. doi: 10.1007/978-1-49399173-0_1

Dabas, Y., Xess, I., and Kale, P. (2017). Molecular and antifungal susceptibility study on trichosporonemia and emergence of Trichosporon mycotoxinivorans as a bloodstream pathogen. Med. Mycol. 55, 518-527. doi: 10.1093/mmy/myw100

Danicke, S., Kersten, S., Valenta, H., and Breves, G. (2012). Inactivation of deoxynivalenol-contaminated cereal grains with sodium metabisulfite: a review of procedures and toxicological aspects. Mycotoxin Res. 28, 199-218. doi: 10. 1007/s12550-012-0139-6

Dhakal, R., Chai, C., Karan, R., Windham, G. L., Williams, W. P., and Subudhi, P. K. (2017). Expression profiling coupled with in-silico mapping identifies candidate genes for reducing aflatoxin accumulation in maize. Front. Plant Sci. 8:503. doi: $10.3389 /$ fpls.2017.00503

Eddy, S. R. (1998). Profile hidden Markov models. Bioinformatics 14, 755-763. doi: 10.1093/bioinformatics/14.9.755

Edgar, R. C. (2004). MUSCLE: a multiple sequence alignment method with reduced time and space complexity. BMC Bioinform. 5:113. doi: 10.1186/1471-21055-113

el-Sharkawy, S., and Abul-Hajj, Y. J. (1988). Microbial cleavage of zearalenone. Xenobiotica 18, 365-371. doi: 10.3109/00498258809041672

Emanuelsson, O., Brunak, S., von Heijne, G., and Nielsen, H. (2007). Locating proteins in the cell using TargetP, SignalP and related tools. Nat. Protoc. 2, 953-971. doi: 10.1038/nprot.2007.131

Emanuelsson, O., Nielsen, H., Brunak, S., and von Heijne, G. (2000). Predicting subcellular localization of proteins based on their N-terminal amino acid sequence. J. Mol. Biol. 300, 1005-1016. doi: 10.1006/jmbi.2000.3903

Fraaije, M. W., Kamerbeek, N. M., van Berkel, W. J., and Janssen, D. B. (2002). Identification of a Baeyer-Villiger monooxygenase sequence motif. FEBS Lett. 518, 43-47. doi: 10.1016/s0014-5793(02)02623-6

Fu, L., Niu, B., Zhu, Z., Wu, S., and Li, W. (2012). CD-HIT: accelerated for clustering the next-generation sequencing data. Bioinformatics 28, 3150-3152. doi: 10.1093/bioinformatics/bts565

Garcia, S. O., Feltrin, A. C. P., and Garda-Buffon, J. (2018). Zearalenone reduction by commercial peroxidase enzyme and peroxidases from soybean bran and rice bran. Food Addit. Contam. Part A Chem. Anal. Control Expo. Risk Assess. 35, 1819-1831. doi: 10.1080/19440049.2018.1486044

Godio, R. P., Fouces, R., and Martín, J. F. (2007). A squalene epoxidase is involved in biosynthesis of both the antitumor compound clavaric acid and sterols in the basidiomycete H. sublateritium. Chem. Biol. 14, 1334-1346. doi: 10.1016/j. chembiol.2007.10.018

Griffiths-Jones, S., Bateman, A., Marshall, M., Khanna, A., and Eddy, S. R. (2003). Rfam: an RNA family database. Nucl. Acids Res. 31, 439-441. doi: 10.1093/nar/ gkg006

Gutierrez-Fernandez, J., Vaquero, M. E., Prieto, A., Barriuso, J., Martinez, M. J., and Hermoso, J. A. (2014). Crystal structures of Ophiostoma piceae sterol esterase: structural insights into activation mechanism and product release. J. Struct. Biol. 187, 215-222. doi: 10.1016/j.jsb.2014.07.007

Holt, C., and Yandell, M. (2011). MAKER2: an annotation pipeline and genomedatabase management tool for second-generation genome projects. BMC Bioinform. 12:491. doi: 10.1186/1471-2105-12-491

Huang, L., Zhang, H., Wu, P., Entwistle, S., Li, X., Yohe, T., et al. (2018). dbCAN-seq: a database of carbohydrate-active enzyme (CAZyme) sequence and annotation. Nucl. Acids Res. 46, D516-D521. doi: 10.1093/nar/gkx894

Huerta-Cepas, J., Szklarczyk, D., Forslund, K., Cook, H., Heller, D., Walter, M. C., et al. (2016). eggNOG 4.5: a hierarchical orthology framework with improved functional annotations for eukaryotic, prokaryotic and viral sequences. $\mathrm{Nucl}$. Acids Res. 44, D286-D293. doi: 10.1093/nar/gkv1248

Hussein, H. S., and Brasel, J. M. (2001). Toxicity, metabolism, and impact of mycotoxins on humans and animals. Toxicology 167, 101-134. doi: 10.1016/ s0300-483x(01)00471-1

Jain, M., Olsen, H. E., Paten, B., and Akeson, M. (2016). The oxford nanopore minion: delivery of nanopore sequencing to the genomics community. Genome Biol. 17:239. doi: 10.1186/s13059-016-1103-0

Jeske, L., Placzek, S., Schomburg, I., Chang, A., and Schomburg, D. (2019). BRENDA in 2019: a European ELIXIR core data resource. Nucl. Acids Res. 47, D542-D549. doi: 10.1093/nar/gky1048

Karlovsky, P., Suman, M., Berthiller, F., De Meester, J., Eisenbrand, G., Perrin, I., et al. (2016). Impact of food processing and detoxification treatments on mycotoxin contamination. Mycotoxin Res. 32, 179-205. doi: 10.1007/s12550016-0257-7

Koren, S., Walenz, B. P., Berlin, K., Miller, J. R., Bergman, N. H., and Phillippy, A. M. (2017). Canu: scalable and accurate long-read assembly via adaptive k-mer weighting and repeat separation. Genome Res. 27, 722-736. doi: 10.1101/ gr.215087.116

Korf, I. (2004). Gene finding in novel genomes. BMC Bioinform. 5:59. doi: 10.1186/ 1471-2105-5-59

Kosawang, C., Karlsson, M., Vélëz, H., Rasmussen, P. H., Collinge, D. B., Jensen, B., et al. (2014). Zearalenone detoxification by zearalenone hydrolase is important for the antagonistic ability of Clonostachys rosea against mycotoxigenic Fusarium graminearum. Fungal Biol. 118, 364-373. doi: 10.1016/j.funbio.2014. 01.005

Kozma, E., Brown, E., Ellis, E. M., and Lapthorn, A. J. (2003). The high resolution crystal structure of rat liver AKR7A1: understanding the substrate specificites of the AKR7 family. Chem. Biol. Interact. 143-144, 289-297. doi: 10.1016/s00092797(02)00186-2

Krivák, R., and Hoksza, D. (2018). P2Rank: machine learning based tool for rapid and accurate prediction of ligand binding sites from protein structure. J. Cheminform. 10:39. doi: 10.1186/s13321-018-0285-8

Krogh, A., Larsson, B., von Heijne, G., and Sonnhammer, E. L. (2001). Predicting transmembrane protein topology with a hidden Markov model: application to complete genomes. J. Mol. Biol. 305, 567-580. doi: 10.1006/jmbi.2000.4315

Kuiper-Goodman, T. (1995). Mycotoxins: risk assessment and legislation. Toxicol. Lett. 82-83, 853-859. doi: 10.1016/0378-4274(95)03599-0

Lechner, M., Findeiß, S., Steiner, L., Marz, M., Stadler, P. F., and Prohaska, S. J. (2011). Proteinortho: detection of (co-) orthologs in large-scale analysis. BMC Bioinform. 12:124. doi: 10.1186/1471-2105-12-124

Letunic, I., and Bork, P. (2019). Interactive Tree Of Life (iTOL) v4: recent updates and new developments. Nucl. Acids Res. 47, W256-W259. doi: 10.1093/nar/ gkz239

Liu, X.-Z., Wang, Q.-M., Göker, M., Groenewald, M., Kachalkin, A., Lumbsch, H. T., et al. (2015). Towards an integrated phylogenetic classification of the tremellomycetes. Stud. Mycol. 81, 85-147. doi: 10.1016/j.simyco.2015.12.001

Loi, M., Fanelli, F., Liuzzi, V. C., Logrieco, A. F., and Mule, G. (2017). Mycotoxin biotransformation by native and commercial enzymes: present and future perspectives. Toxins 9:111. doi: 10.3390/toxins9040111

Lyagin, I., and Efremenko, E. (2019). Enzymes for detoxification of various mycotoxins: origins and mechanisms of catalytic action. Molecules 24:2362. doi: 10.3390/molecules24132362

Marimón Sibaja, K. V., de Oliveira Garcia, S., Feltrin, A. C. P., Diaz Remedi, R., Cerqueira, M. B. R., Badiale-Furlong, E., et al. (2019). Aflatoxin biotransformation by commercial peroxidase and its application in contaminated food. J. Chem. Technol. Biotechnol. 94, 1187-1194. doi: 10.1002/ jctb. 5865 
Mascotti, M. L., Lapadula, W. J., and Ayub, M. J. (2015). The origin and evolution of Baeyer-Villiger monooxygenases (BVMOs): an ancestral family of flavin monooxygenases. PLoS One 10:e0132689. doi: 10.1371/journal.pone.0132689

Molnar, O., Schatzmayr, G., Fuchs, E., and Prillinger, H. (2004). Trichosporon mycotoxinivorans sp. nov., a new yeast species useful in biological detoxification of various mycotoxins. Syst. Appl. Microbiol. 27, 661-671. doi: 10.1078/ 0723202042369947

Park, J., Lee, S., Choi, J., Ahn, K., Park, B., Park, J., et al. (2008). Fungal cytochrome P450 database. BMC Genom. 9:402. doi: 10.1186/1471-2164-9-402

Peng, W., Ko, T.-P., Yang, Y., Zheng, Y., Chen, C.-C., Zhu, Z., et al. (2014). Crystal structure and substrate-binding mode of the mycoestrogen-detoxifying lactonase ZHD from Clonostachys rosea. RSC Adv. 4, 62321-62325. doi: 10. 1039/C4RA12111B

Peraica, M., Radic, B., Lucic, A., and Pavlovic, M. (1999). Toxic effects of mycotoxins in humans. Bull. World Health Organ. 77, 754-766.

Qi, Q., Yang, W. J., Zhou, H. J., Ming, D. M., Sun, K. L., Xu, T. Y., et al. (2017). The structure of a complex of the lactonohydrolase zearalenone hydrolase with the hydrolysis product of zearalenone at 1.60 A resolution. Acta Crystallogr. F. Struct. Biol. Commun. 73(Pt 7), 376-381. doi: 10.1107/S2053230X1700 7713

Rawlings, N. D., and Barrett, A. J. (1999). MEROPS: the peptidase database. Nucl. Acids Res. 27, 325-331. doi: 10.1093/nar/27.1.325

Rawlings, N. D., Barrett, A. J., and Bateman, A. (2010). MEROPS: the peptidase database. Nucl. Acids Res. 38(Suppl. 1), D227-D233. doi: 10.1093/nar/ gkp971

Rawlings, N. D., Barrett, A. J., Thomas, P. D., Huang, X., Bateman, A., and Finn, R. D. (2017). The MEROPS database of proteolytic enzymes, their substrates and inhibitors in 2017 and a comparison with peptidases in the PANTHER database. Nucl. Acids Res. 46, D624-D632. doi: 10.1093/nar/gkx1134

Riebel, A., de Gonzalo, G., and Fraaije, M. W. (2013). Expanding the biocatalytic toolbox of flavoprotein monooxygenases from Rhodococcus jostii RHA1. J. Mol. Catal. B Enzym. 88, 20-25. doi: 10.1016/j.molcatb.2012.11.009

Rokas, A., Mead, M. E., Steenwyk, J. L., Raja, H. A., and Oberlies, N. H. (2020). Biosynthetic gene clusters and the evolution of fungal chemodiversity. Nat. Prod. Rep. [Epub ahead of print] doi: 10.1039/c9np00045c

Ruan, J., and Li, H. (2020). Fast and accurate long-read assembly with wtdbg2. Nat. Methods 17, 155-158. doi: 10.1038/s41592-019-0669-3

Sayers, E. W., Beck, J., Brister, J. R., Bolton, E. E., Canese, K., Comeau, D. C., et al. (2020). Database resources of the national center for biotechnology information. Nucleic Acids Res. 48, D9-D16. doi: 10.1093/nar/gkz899

Schatzmayr, G., Zehner, F., Taubel, M., Schatzmayr, D., Klimitsch, A., Loibner, A. P., et al. (2006). Microbiologicals for deactivating mycotoxins. Mol. Nutr. Food Res. 50, 543-551. doi: 10.1002/mnfr.200500181

Scheer, M., Grote, A., Chang, A., Schomburg, I., Munaretto, C., Rother, M., et al. (2011). BRENDA, the enzyme information system in 2011. Nucl. Acids Res. 39, D670-D676. doi: 10.1093/nar/gkq1089

Seppey, M., Manni, M., and Zdobnov, E. M. (2019). BUSCO: assessing genome assembly and annotation completeness. Methods Mol. Biol. 1962, 227-245. doi: 10.1007/978-1-4939-9173-0_14

Takahashi-Ando, N., Kimura, M., Kakeya, H., Osada, H., and Yamaguchi, I. (2002). A novel lactonohydrolase responsible for the detoxification of zearalenone: enzyme purification and gene cloning. Biochem. J. 365(Pt 1), 1-6. doi: 10.1042/ BJ20020450

Tang, Y., Xiao, J., Chen, Y., Yu, Y., Xiao, X., Yu, Y., et al. (2013). Secretory expression and characterization of a novel peroxiredoxin for zearalenone detoxification in Saccharomyces cerevisiae. Microbiol. Res. 168, 6-11. doi: 10. 1016/j.micres.2012.08.002

Tarailo-Graovac, M., and Chen, N. (2009). Using repeatmasker to identify repetitive elements in genomic sequences. Curr. Protoc. Bioinform. Chapter 4, Unit 10. doi: 10.1002/0471250953.bi0410s25

Trott, O., and Olson, A. J. (2010). AutoDock Vina: improving the speed and accuracy of docking with a new scoring function, efficient optimization, and multithreading. J. Comput. Chem. 31, 455-461. doi: 10.1002/jcc.21334

Urban, M., Pant, R., Raghunath, A., Irvine, A. G., Pedro, H., and HammondKosack, K. E. (2015). The pathogen-host interactions database (PHI-base): additions and future developments. Nucl. Acids Res. 43, D645-D655. doi: 10. 1093/nar/gku1165

Vanhoutte, I., Audenaert, K., and De Gelder, L. (2016). Biodegradation of mycotoxins: tales from known and unexplored worlds. Front. Microbiol. 7:561. doi: 10.3389/fmicb.2016.00561

Vekiru, E., Hametner, C., Mitterbauer, R., Rechthaler, J., Adam, G., Schatzmayr, G., et al. (2010). Cleavage of zearalenone by Trichosporon mycotoxinivorans to a novel nonestrogenic metabolite. Appl. Environ. Microbiol. 76, 2353-2359. doi: 10.1128/AEM.01438-09

Walker, B. J., Abeel, T., Shea, T., Priest, M., Abouelliel, A., Sakthikumar, S., et al. (2014). Pilon: an integrated tool for comprehensive microbial variant detection and genome assembly improvement. PLoS One 9:e112963. doi: 10.1371/journal. pone.0112963

Webb, B., and Sali, A. (2017). Protein structure modeling with MODELLER. Methods Mol. Biol. 1654, 39-54. doi: 10.1007/978-1-4939-7231-9_4

Winnenburg, R., Baldwin, T. K., Urban, M., Rawlings, C., Köhler, J., and Hammond-Kosack, K. E. (2006). PHI-base: a new database for pathogen host interactions. Nucleic Acids Res. 34(Suppl. 1), D459-D464. doi: 10.1093/nar/ gkj047

Winnenburg, R., Urban, M., Beacham, A., Baldwin, T. K., Holland, S., Lindeberg, M., et al. (2007). PHI-base update: additions to the pathogen-host interaction database. Nucl. Acids Res. 36(Suppl. 1), D572-D576. doi: 10.1093/nar/gkm858

Yin, Y., Mao, X., Yang, J., Chen, X., Mao, F., and Xu, Y. (2012). dbCAN: a web resource for automated carbohydrate-active enzyme annotation. Nucl. Acids Res. 40, W445-W451. doi: 10.1093/nar/gks479

Yu, Y., Wu, H., Tang, Y., and Qiu, L. (2012). Cloning, expression of a peroxiredoxin gene from Acinetobacter sp. SM04 and characterization of its recombinant protein for zearalenone detoxification. Microbiol. Res. 167, 121-126. doi: 10. 1016/j.micres.2011.07.004

Zarev, Y., Naessens, T., Theunis, M., Elgorashi, E., Apers, S., Ionkova, I., et al. (2020). In vitro antigenotoxic activity, in silico ADME prediction and protective effects against aflatoxin B1 induced hepatotoxicity in rats of an Erythrina latissima stem bark extract. Food Chem. Toxicol. 135:110768. doi: 10.1016/j.fct. 2019.110768

Conflict of Interest: The authors declare that the research was conducted in the absence of any commercial or financial relationships that could be construed as a potential conflict of interest.

Copyright (C) 2020 Sun, Xia and Ming. This is an open-access article distributed under the terms of the Creative Commons Attribution License (CC BY). The use, distribution or reproduction in other forums is permitted, provided the original author(s) and the copyright owner(s) are credited and that the original publication in this journal is cited, in accordance with accepted academic practice. No use, distribution or reproduction is permitted which does not comply with these terms. 